\title{
Index of orthodontic treatment need as a predictor of orthodontic treatment uptake
}

\author{
Nicky A. Mandall, ${ }^{a}$ Jean Wright, ${ }^{\mathrm{b}}$ Frances Conboy, ${ }^{\mathrm{c}}$ Elizabeth Kay, ${ }^{\mathrm{d}}$ Linda Harvey, ${ }^{\mathrm{e}}$ and Kevin D. O'Brien ${ }^{\mathrm{d}}$ \\ Manchester, United Kingdom
}

Introduction: The aim of this study was to evaluate whether the index of orthodontic treatment need (IOTN) could be weighted by using consumer-based sociodental measures to predict the uptake of orthodontic services. Methods: The sample consisted of 525 schoolchildren, 11 to 12 years old, from Greater Manchester, United Kingdom. Child-perceived IOTN aesthetic component (AC), examiner IOTN AC and dental health component, and child socioeconomic status (Townsend score) were recorded. Two consumer sociodental measures (utility and oral aesthetic subjective impact scale values) were recorded. Three years later, the proportion of the subjects who had received orthodontic treatment or were on a waiting list for orthodontic treatment was recorded, and the rate of service uptake was determined. Results: Sociodental indicators did not predict uptake of orthodontic services. A child with higher normative clinical treatment need was 3 times more likely to receive orthodontic treatment than a child with low clinical need $(P<.05)$. Conclusions: Consumer-based sociodental information does not predict future use of orthodontic services. Factors such as clinical IOTN and child-perceived IOTN AC will adequately predict use of orthodontic services. (Am J Orthod Dentofacial Orthop 2005;128:703-7)

$\mathbf{T}$ The aim of this study was to evaluate whether the index of orthodontic treatment need (IOTN) ${ }^{1}$ can be weighted by using consumer-based sociodental measures to predict the uptake of orthodontic services.

The IOTN was developed to measure treatment need in people or groups to ensure that patients with the greatest needs receive treatment and to aid in orthodontic manpower planning. More recently, the index of complexity, outcome and need (ICON) $)^{2}$ has been internationally validated with a panel of 97 orthodontists. Both indexes were developed from a professional viewpoint and thus measure normative need. Although both indexes measure outcomes relevant to malocclusion traits, they might not be totally relevant to consumers' functional and social treatment requirements. ${ }^{3-6}$

The literature contains few studies of consumer values in orthodontics; however, it has been suggested that consumer values, such as utility values ${ }^{7}$ and oral aesthetic subjective impact scores (OASIS), ${ }^{8}$ might prompt people to use orthodontic services. These stud-

\footnotetext{
aSenior lecturer, Unit of Orthodontics, University Dental Hospital of Manchester. ${ }^{b}$ Research fellow, University Dental Hospital of Manchester.

${ }^{\mathrm{c}}$ Research associate, University Dental Hospital of Manchester.

${ }^{\mathrm{d}}$ Professor, Unit of Oral Health and Development, University of Manchester.

e Research assistant, University Dental Hospital of Manchester.

Reprint requests to: Dr N. A. Mandall, Oral Health and Development, University Dental Hospital of Manchester, Higher Cambridge Street, Manchester, M15 6FH, United Kingdom; e-mail: Nicky@fs1.den.man.ac.uk.

Submitted, February 2004; revised and accepted, October 2004. 0889-5406/\$30.00

Copyright $(9) 2005$ by the American Association of Orthodontists. doi:10.1016/j.ajodo.2004.10.011
}

ies suggested that seekers of orthodontic treatment placed a higher value on esthetic tooth appearance than nonseekers $(P<.05)$.

Social and consumer values might play important roles in prompting people to seek treatment, and this in turn could be used to predict the use of orthodontic services. Perhaps such predictors can be derived from a combined measure of treatment need based on clinician and patient or consumer factors or consumer-weighted IOTN scores. This concept formed the focus for this study.

\section{MATERIAL AND METHODS}

We used United Kingdom census data, ${ }^{9}$ health district dentist lists, and information from the central government agency that pays for orthodontic care (Dental Practice Board) to calculate the ratios of dentists and orthodontists to 10- to 14-year-olds. Fifteen schools were then randomly sampled from Greater Manchester and Lancashire, where these ratios were high and low.

A previous study ${ }^{8}$ showed that children with a mean OASIS score represented $15 \%$ of orthodontic treatment uptake, and children with scores +1 SD represented $25 \%$ uptake of treatment. To give a study with an alpha of 0.05 and beta 0.1 , we calculated that we needed a minimum sample size of 245 children (11-12 years old). To allow for minimum response rates of $60 \%$ at baseline (DC1) and 80\% at the 3-year follow-up (DC2), 
we needed to sample 510 children. Our target sample was set at 525 children as an overestimate.

Because children in the DC1 sample might have sought orthodontic treatment as a result of participating in our study, we also surveyed a control sample at DC2, comprising 525 randomly selected control students who had not participated at DC1.

The following data were collected from the DC1 sample at school:

- Demographic information: age, sex, socioeconomic status (Townsend score). ${ }^{10}$ The Townsend score is a social deprivation score based on census variables and derived from zip code data. It takes into account 4 factors: percentage of economically active adults who are unemployed; percentage of permanent households with no car; percentage of households that are overcrowded; percentage of permanent households in rental housing. As Townsend score increases, social deprivation also increases.

- Normative measure of treatment need: IOTN aesthetic component (AC) and dental health component (DHC) were recorded by a calibrated examiner (N.A.M.).

- Consumer measures: utility value, OASIS score, and child self-perceived IOTN AC score. A utility value theoretically represents a condensation of biological, physical, sociological, and psychological parameters that can influence a person's sense of well-being or quality of life. Therefore, the subject's evaluation of given health states is measured. We calculated utility values for the subjects' current status using the time trade-off method described by Fox. ${ }^{7}$ In this method, utility scores ranging from 0 to 1 are calculated by using some pictures from the IOTN AC. A high utility score indicated that a child places a higher value on esthetic tooth appearance.

Students completed the OASIS questionnaire by responding to questions on a 7-point Likert scale. ${ }^{8}$ The questions assessed how the children felt about their teeth, whether any comments were directed toward their teeth, whether they been teased about their teeth, whether they avoided smiling or covered their mouths because of the appearance of their teeth, and their self-perceived IOTN AC score. The scores are summed to give a total OASIS score.

Three years later, at DC2, the same schools were revisited to identify children who had received or were on a waiting list for orthodontic treatment. This became our measure of use of orthodontic services. Children who were absent at this visit were sent the questionnaire and asked to return it.

\section{Statistical analysis}

Summary statistics were produced. Use of orthodontic services for children participating at DC1 and the control group were compared by using the chisquare statistic. The predictive value of the baseline variables on use of services was evaluated with multiple logistic regression analysis. The following variables were entered into the model: (1) age, sex, socioeconomic status, and ratio of dentists and orthodontists to 10- to 14-year olds; (2) clinician-measured IOTN AC and DHC; (3) utility value, OASIS score, and child self-perceived IOTN AC score.

Sensitivity and specificity values were calculated for statistically significant baseline variables. Thus, the relative merit of adding additional information to IOTN to predict use of orthodontic services was evaluated.

\section{RESULTS}

At DC1, data for 400 children were available for analysis, and, of these, we obtained information on use of services for 325 at DC2. This resulted in an overall response rate of $81 \%$. Detailed information on response rates and reasons for nonresponse are summarized in Table I. The final sample of 325 met the requirement of 245 required by the initial sample size calculation. Forty-three percent had either received or were due to receive orthodontic treatment $(50.9 \%$ girls, $49.1 \%$ boys), and $57 \%$ had not used orthodontic services (53\% girls, $47 \%$ boys). Further descriptive statistics are given in Table II.

Table III shows use of services for children with clinical need, defined as IOTN AC scores greater than 5 or IOTN DHC scores of 4 or 5. Approximately half of the children who had a clear clinical need for treatment were receiving it.

Before further data analysis was undertaken, we ensured that the children in the DC1 baseline sample had not been influenced to seek orthodontic treatment because of participating in our study. No statistically significant difference was observed for use of orthodontic services between the original sample and the control group (chi-square value $0.48,1 \mathrm{df}, P>.05$ ).

Table IV includes the results of the multiple logistic regression analysis: sociodental indicators (OASIS and utility score) did not influence use of orthodontic services. However, when the component questions of OASIS were considered separately, we found that a child who did not report being teased about his or her teeth was half as likely to use orthodontic services as a child who was teased (odds ratio [OR] $0.4, P<.05$ ).

Nevertheless, there was a predictive effect of examiner-recorded and child-recorded IOTN on use of 
Table I. Response rates and reasons for nonresponse at DC1 and DC2

\begin{tabular}{lcrrrrrr}
\hline & & \multicolumn{5}{c}{ Reasons for nonresponse } \\
\cline { 3 - 6 } & Target sample & Left school & Refused & Absent & In appliances & Final sample & \% response \\
\hline DC1 (age 11-12 years) & 525 & 50 & 25 & 31 & 19 & 400 & 76 \\
DC2 (age 14-15 years) & 400 & 0 & 7 & 68 & NA & 325 & 81 \\
Controls & $473 *$ & 0 & 13 & 77 & NA & 383 & 81 \\
\hline
\end{tabular}

NA, Not applicable.

*Increased target sample to allow for nonresponse.

Table II. Descriptive statistics according to use of orthodontic services

\begin{tabular}{|c|c|c|c|}
\hline & & Use of orthodontic services & No use of orthodontic services \\
\hline \multirow[t]{2}{*}{ Age/years (SD) } & & $12.1(0.3)$ & $12.2(0.3)$ \\
\hline & & CI $12.1-12.2$ & CI $12.1-12.3$ \\
\hline \multirow[t]{3}{*}{ IOTN AC (examiner) (\%) } & $1-4$ & $14(14)$ & $131(56.9)$ \\
\hline & $5-7$ & $45(45)$ & $76(33.1)$ \\
\hline & $8-10$ & $41(41)$ & $23(10.0)$ \\
\hline \multirow[t]{3}{*}{ IOTN AC (child) (\%) } & $1-4$ & $72(72)$ & $203(88.3)$ \\
\hline & $5-7$ & $25(25)$ & $21(9.1)$ \\
\hline & $8-10$ & $3(3)$ & $6(2.6)$ \\
\hline \multirow[t]{3}{*}{ IOTN DHC (examiner) $(\%)$} & $1-2$ & $8(8)$ & $87(37.8)$ \\
\hline & 3 & $19(19)$ & $68(29.6)$ \\
\hline & $4-5$ & $73(73)$ & $75(32.6)$ \\
\hline \multirow{2}{*}{\multicolumn{2}{|c|}{ Mean utility score (AC 8) }} & $0.80(0.20)$ & $0.73(0.26)$ \\
\hline & & CI $0.76-0.83$ & CI $0.69-0.76$ \\
\hline \multirow{2}{*}{\multicolumn{2}{|c|}{ Mean utility score (AC 5) }} & $0.86(0.19)$ & $0.84(0.19)$ \\
\hline & & CI $0.82-0.90$ & CI $0.81-0.86$ \\
\hline \multirow{2}{*}{\multicolumn{2}{|c|}{ Mean utility score (AC 3) }} & $0.96(0.12)$ & $0.94(0.14)$ \\
\hline & & CI $0.94-0.98$ & CI $0.93-0.96$ \\
\hline \multirow[t]{2}{*}{ Mean OASIS } & & $22.5(6.7)$ & $19.7(6.1)$ \\
\hline & & CI 21.2-23.9 & CI 18.9-20.5 \\
\hline \multirow{2}{*}{$\begin{array}{l}\text { Patient-to-dentist ratio } \\
\mathrm{n}(\%)\end{array}$} & Unfavorable & $55(55)$ & $98(42.6)$ \\
\hline & Favorable & $45(45)$ & $132(57.4)$ \\
\hline
\end{tabular}

CI, $95 \%$ confidence interval.

Table III. Subjects receiving orthodontic treatment who had clinical need for treatment

\begin{tabular}{lc}
\hline Clinical need for treatment & $\begin{array}{c}\text { Children receiving orthodontic } \\
\text { treatment }(\%)\end{array}$ \\
\hline IOTN DHC score 4 and 5 & 49.3 \\
IOTN AC score $>5$ & 49.4 \\
Either IOTN DHC score 4 and 5 & 45.2 \\
$\quad$ or IOTN AC score $>5$ & \\
\hline
\end{tabular}

services: as the self-perceived IOTN AC score increased, the child became more likely to receive treatment $(P<.05)$. Increases in examiner IOTN AC and DHC also caused the children to be more likely to receive treatment $(P<.05$ and $P<.001$, respectively).

It appeared that older subjects were half as likely to take up orthodontic services $(\mathrm{OR}=0.5, P<.05)$. In addition, if a child lived where there was an unfavorable dentist-population ratio, he or she was half as likely to receive orthodontic treatment as a child in a favorable dentist-population ratio area $(\mathrm{OR}=0.4, P<.05)$.

\section{Sensitivity and specificity analysis}

Table $\mathrm{V}$ shows the sensitivity and specificity of the variables in the regression model for predicting use of orthodontic services. Sensitivity or true positive values (when the baseline variable predicted use of services and the child received treatment) were between $40.7 \%$ and $50.6 \%$. Positive predictive values increased gradually from $66.1 \%$ to $71.2 \%$, as each baseline variable was added to the model.

Specificity or true negative values (when the baseline variable predicted no use of services and the child did not receive treatment) ranged from $90.9 \%$ to $91.9 \%$ with negative predictive values increasing from $77.9 \%$ to $80.1 \%$ when IOTN AC, DHC, and teasing variables were in the model. Adding the remaining variables did not further increase the negative predictive value. 
Table IV. Multiple logistic regression analysis to show influence of IOTN and patient-based variables on use of orthodontic services

\begin{tabular}{llrrrrr}
\hline Dependent variable & Statistically significant independent variables & Z value & SE & P value & $95 \%$ CI & OR \\
\hline Use of orthodontic services (1) & Examiner IOTN AC (2) & 3.09 & 1.33 & .002 & $1.56-7.31$ & 3.4 \\
& Examiner IOTN DHC (2) & 3.80 & 1.28 & $<.001$ & $1.88-7.26$ & 3.7 \\
& Child perceived IOTN AC (2) & 2.57 & 0.93 & .01 & $1.25-5.23$ & 2.6 \\
& Teasing about teeth (3) & -2.78 & 0.13 & .005 & $0.23-0.77$ & 0.4 \\
& Dentist:population ratio (4) & -2.68 & 0.13 & .007 & $0.25-0.80$ & 0.4 \\
& Age & -2.55 & 0.14 & .01 & $0.25-0.84$ & 0.5 \\
\hline
\end{tabular}

(1), $0=$ no, $1=$ yes.

(2), As IOTN score increases, need for treatment increases.

(3), 1 = teased, 2 = not teased.

(4), Dentist to 10-14 year old population ratio: $1=$ favorable, $2=$ unfavorable.

Table V. Sensitivity and specificity values for statistically significant baseline variables that predict use of orthodontic services

\begin{tabular}{|c|c|c|c|c|c|c|}
\hline & IOTN AC & $+I O T N D H C$ & $\begin{array}{l}+ \text { Teasing about } \\
\text { teeth }\end{array}$ & $\begin{array}{c}+ \text { Dentist to } 12 \text {-year-old } \\
\text { ratio }\end{array}$ & $+A g e$ & $\begin{array}{c}+ \text { Child-perceived } \\
\text { IOTN AC }\end{array}$ \\
\hline Sensitivity & 40.7 & 38.4 & 50.6 & 44.0 & 45.1 & 46.2 \\
\hline Specificity & 90.9 & 90.9 & 86.6 & 89.5 & 91.4 & 91.9 \\
\hline Positive predictive value & 66.1 & 64.8 & 62.2 & 64.5 & 69.5 & 71.2 \\
\hline Negative predictive value & 77.9 & 77.2 & 80.1 & 78.6 & 79.3 & 79.7 \\
\hline $\begin{array}{l}\text { Probability of predicting use of } \\
\text { services when child does not } \\
\text { have treatment }\end{array}$ & 9.1 & 9.1 & 13.4 & 10.5 & 8.6 & 8.1 \\
\hline $\begin{array}{l}\text { Probability of predicting no } \\
\text { use of services when child } \\
\text { does have treatment }\end{array}$ & 59.3 & 61.5 & 49.5 & 56.0 & 55.0 & 53.9 \\
\hline $\begin{array}{l}\text { Probability of child having no } \\
\text { treatment when model } \\
\text { predicts use of services }\end{array}$ & 33.9 & 35.2 & 37.8 & 35.5 & 30.5 & 28.8 \\
\hline $\begin{array}{l}\text { Probability of child having } \\
\text { treatment when model } \\
\text { predicts no use of services }\end{array}$ & 22.1 & 22.8 & 19.9 & 21.4 & 20.8 & 20.3 \\
\hline Total classified correctly & 75.7 & 75.0 & 75.7 & 75.7 & 77.3 & 78.0 \\
\hline
\end{tabular}

The remaining probability values in Table $\mathrm{V}$ and the "total classified correctly" did not show a clinically significant increase as each baseline variable was added to the model. The total predictive probability of the model for a subject to use orthodontic services was $75.7 \%$ for IOTN AC alone and only increased to $78.0 \%$ when all other statistically significant baseline variables were added.

\section{DISCUSSION}

The study showed that a child's age, the dentistpopulation ratio in the local community, and the child's normative need as measured by IOTN are predictors of the use of orthodontic services. Conversely, sociodental consumer based measures (OASIS and utility values) did not have an influence. The exceptions to this were children who were teased about their teeth and who perceived a poor esthetic tooth appearance; these chil- dren were more likely to receive orthodontic treatment. It is difficult to compare these findings with previous literature because no studies have prospectively investigated the predictive effect of these variables on the use of services.

One of our most important findings was that, if epidemiological data are required for orthodontic manpower planning, the use of examiner-recorded IOTN AC data might be sufficient. This is because the total number of subjects correctly classified by our model did not increase much when other variables were added. Epidemiological factors such as age and dentist-population ratios are likely to already be known for a given sample and geographical area.

However, clinicians might still wish to consider factors such as patient-perceived IOTN AC scores and teasing when deciding whether to treat a patient. This is supported by Shaw et al, ${ }^{11}$ who reported that $60 \%$ of 
the children who were teased about their teeth were upset.

In addition, although our model suggests that IOTN $\mathrm{AC}$ is sufficient for assessing need and thus manpower planning, it is unlikely that a service will be financed purely because of esthetic need. As a result, the IOTN DHC is just as important when assessing need because it takes into account the dental health risks of malocclusion. This should also ensure that children with the most severe malocclusions are treated because patients with impacted canines might have low AC scores but high DHC scores.

It is difficult to suggest possible reasons for the lack of effect of patient-derived measures on use of orthodontic services. One reason is that attendance at a dentist and the consequent "gatekeeper" role of the dentist for making a referral has an overriding influence on whether a person seeks orthodontic treatment. This hypothesis was supported by our finding that the dentist-population ratio had a positive predictive effect on orthodontic treatment uptake. This finding is similar to that of O'Mullane and Robinson ${ }^{12}$ about the use of general dental services. They also reported that dentalservice use was lower in socially deprived populations except where the dentist-population ratio was favorable. It is possible that the dentist-population ratios were generally favorable in our study and thus counteracted any influence of social deprivation on uptake of orthodontic services.

The lack of effect of orthodontic-population ratio on use of orthodontic services was surprising but can be explained by the narrow range of values in this region (1:4937 to $1: 6845)$. Alternatively, children might be accessing orthodontic providers where unfavorable ratios exist but waiting longer for treatment.

\section{CONCLUSIONS}

1. Sociodental measures (OASIS and utility scores) do not predict uptake of orthodontic services. Therefore, it does not seem to be beneficial to collect additional consumer-based information to predict future use of orthodontic services and manpower. Additionally, sociodental information cannot be used to weight IOTN to provide a consumer-based element to normative treatment-need measures.
2. Use of orthodontic services is more likely to be influenced by normative clinical need (IOTN). IOTN AC data might be sufficient for epidemiological studies in predicting use of services. However, assessment of future manpower requirements will probably also require IOTN DHC data to fully assess dental health risks.

3. Children who are teased about their teeth are more likely to receive orthodontic treatment; teasing appears to be a motivator for seeking care.

4. Children in areas with a shortage of dentists are less likely to receive orthodontic treatment. However, despite this, socially deprived children do not seem to be disadvantaged in terms of receiving orthodontic treatment.

We thank the NHS R \& D Programme on Primary Dental Care, United Kingdom, and the participating schools in Greater Manchester.

\section{REFERENCES}

1. Brook PH, Shaw WC. The development of an index of orthodontic treatment priority. Eur J Orthod 1989;11:309-20.

2. Daniels C, Richmond S. The development of the index of complexity, outcome and need (ICON). J Orthod 2000;27:149-62.

3. Sheiham A, Croog S. The psychosocial impact of dental disease on individuals and communities. J Behav Med 1981;4:257-71.

4. Sheilham A, Maizels JE, Cushing AM. The concept of need in dental care. Int Dent J 1982;32:265-9.

5. Sheilham A, Maizels JE, Maizels A. New composite indicators of dental health. Community Dental Health 1987;4:407-14.

6. Locker D. Measuring oral health: a conceptual framework. Community Dent Health 1988;5:3-18.

7. Fox D. The utility of anterior tooth appearance [thesis] Manchester, United Kingdom: University of Manchester; 1997.

8. Mandall NA, McCord JF, Blinkhorn AS, Worthington, HV, O'Brien KD. Perceived aesthetic impact of malocclusion and oral self-preception in 14-15 year-old Asian and Caucasian children in Greater Manchester. Eur J Orthod 1999;21:175-83

9. United Kingdom Census. Ethnic group and country of birth. Office of Population Census \& Surveys, General Register Office, Edinburgh, Scotland; 1991.

10. Townsend P. Deprivation. J Soc Policy 1987;16:125-46.

11. Shaw WC, Meek SC, Jones DS. Nicknames, teasing, harassment and the salience of dental features among school children. $\mathrm{Br}$ Dent J 1980;7:75-80.

12. O'Mullane DM, Robinson ME. The distribution of dentists and the uptake of dental treatment by schoolchildren in England. Comm Dent Oral Epidemiol 1977;5:156-9. 